\title{
Obtención de Biogás a Partir de Excremento de Cuy en Condiciones Ambientales en Tacna Perú
}

\section{Obtaining of Biogas from Excrement of Guinea Pig in Environmental Conditions in Tacna Perú}

\author{
' Daladier Castillo Cotrina, ${ }^{2}$ Carlos Tito Vargas.
}

\begin{abstract}
RESUMEN:
El objetivo del trabajo fue obtener biogás a partir del excremento de cuy por fermentación en batch en condiciones ambientales en Tacna-Perú. Se empleó dos mezclas de substratos; una formada por excremento de cuy, rastrojo del alimento vegetal de cuy y agua; y la segunda por excremento de cuw; rastrojo del alimento vegetal del cuy, residuo de grass y agua. Estos substratos fueron prefermentados por separado en condiciones aeróbicas en un prefermentador cilindrico, luego sometidos a una fermentación en batch, anaeróbića, no agitada, en biodigestores cilindricos uno y dos, de 227 litros de capacidad cada uno, en los cuales los substratos prefermentados estuvieron ocupando alrededor de las dos terceras partes del volumen total de los biodigestores. El volumen total de biogás producido en el biodigestor uno fue de 10+ litros en un tiempo de fermentación de 7 meses y 6 dias: y en el biodigestor dos de 452 litros en un tiempo de fermentación de 7 meses y 19 dias.
\end{abstract}

Palabras clave: biogás; biodigestores; excremento de cuy.

\section{ABSTRACT:}

The objective of the work was to obtain biogas from the excrement of guinea pig by fermentation in batch under environmental conditions in Tacna-Peru. Two mixtures of substrates were used: one formed by excrement of guinea pig, stubble of the vegetal food of guinea pig and water; and the second by excrement of guinea pig, stubble of the vegetal food of the guinea pig, remains of grass and water. These substrates were pre fermented separately in aerobic conditions in a cylindrical prefermenter, then they were put under a fermentation in batch, anaterobic, not shaken, in cylindrical biodigestors one and two, of 227 liters of capacity each one, in which the pre fermented substrates were occupying around the two third parts of the total volume of the biodigestors. The lotal volume of biogas produced in the biodigestor one was of $10+4$ liters in a time of fermentation of 7 months and 6 days: and in the biodigestor two of 452 liters in a time of fermentation of 7 months and 19 days.

Keywords: biogas: biodigestores: excrement of guinea pig. \footnotetext{
Maestro en Ciencias con mención en Microbiologia y Biotecnologia. Bioblogo Microbiólogo. Facultad de Ciencias. Uiniversidad Nacional Jorge
Basadre Grohmann

Biólogo Microbiólogo. Facultad de Ciencias. Universidad Nacional Jorge Basadre Grohmann
} 


\section{INTRODUCCIÓN}

En nuestro pais el desarrollo de procesos para obtener biogás es relativamente nuevo. La composición química del biogás es: Metano $\left(\mathrm{CH}_{4}\right): 55$ a $70 \%$; Anhidrido carbónico $\left(\mathrm{CO}_{2}\right)$ : 35 a $40 \%$; Nitrógeno $\left(\mathrm{N}_{2}\right): 0.5$ a $5 \%$ : Sulfuro de hidrógeno $\left(\mathrm{SH}_{2}\right): 0.1 \%$; Hidrógeno $\left(\mathrm{H}_{2}\right)$ : 1 a $3 \%$; Vapor de agua: Trazas. La producción de biogás es un proceso que depende de varios parámetros: actividad bacteriana, temperatura, tiempo de retención, relación Carbono/Nitrógeno, porcentaje de sólidos, $\mathrm{pH}$ (G.A.T.E., 1999)(Hernández, 1990).

Todos los residuos orgánicos (basura de cocina, restos vegetales, restos animales, aguas servidas, aserrines, virutas, bosta y excrementos) son adecuados para ser fermentados anaeróbicamente (en ausencia de oxígeno). Las bacterias consumen el carbono y el nitrógeno y como resultado se produce el biogás o gas de los pantanos. En la producción de biogás es necesario la construcción de la cámara especial denominado biodigestor para que se obtenga la fermentación anaeróbica (sin aire).

Los alimentos principales de las bacterias anaeróbicas, que son los que intervienen en la fermentación, son el carbono (en la forma de carbohidratos) y el nitrógeno (en forma de proteínas, nitratos, amoniaco, etc). El carbono se utiliza para obtener energia y el nitrógeno para la construcción de estructuras celulares. Estas bacterias utilizan carbono con una rapidez unas treinta veces mayor al del uso del nitrógeno. Una razón $\mathrm{C} / \mathrm{N}$ de 30 ( 30 veces más carbono que nitrógeno) permite que la digestión se lleve a cabo a un ritmo óptimo, a condición de que las otras condiciones sean favorables.

En Tacna utilizando el estiércol de cuy como material fermentativo y como inóculo el rumen del estómago de la vaca se ha llegado a obtener, biogás en batch, que al ser encendido originó una llama que tuvo una duración de 10 minutos (Delgado, 2006).

En este trabajo se tuvo como objetivo obtener biogás del excremento de cuy por fermentación en batch en condiciones ambientales en Tacna-Perú.

\section{MATERIALY MÉTODOS}

Se diseñaron y construyeron dos biodigestores cilíndricos metálicos los cuales tuvieron las mismas dimensiones y caracteristicas cada uno con un volumen interior de 227 litros. En el cilindro, en la tapa superior plana, en una de sus tapas roscas cerca del borde, se le acopló un tubo corto vertical con una llave de media, al cual se le dio la función de tubo de descarga del biogás; opuesto a este tubo de descarga cerca del borde del cilindro a otra de sus tapas roscas de $7 \mathrm{~cm}$ de diámetro se le acondicionó cinta teflón para un cierre hermético, para que tuviera como así fue la función de abertura de carga del biodigestor. En la parte lateral del cilindro se le acopló un segundo tubo corto vertical con otra llave de media, el cual tuvo la función de tubo de toma de muestra.
Se trabajó con dos mezclas de substratos. La uno estuvo formado por excremento de cuy, rastrojo del alimento vegetal del cuy y agua; $y$ la dos por excremento de cuy, rastrojo del alimento vegetal del cuy, grass y agua. El excremento de cuy y el rastrojo del alimento vegetal del cuy, por separado, se recogieron manualmente y en sacos de polietileno de criaderos artesanales del cuy. Los materiales en los sacos fueron trasladados a un área de suelo al costado del Bioterio de la Escuela Académico Profesional de Biología Microbiología, ciudad universitaria de la UNJBG de Tacna, para ser extendidos y expuestos al sol para su secado sobre mantas de costales que cubrian la superficie del suelo. El área de extendido para cada substrato fue de $6 \mathrm{~m}^{2}$ con una altura de aproximadamente $15 \mathrm{~cm}$. El residuo de grass es el que resultó de la poda de las áreas verdes de grass de la ciudad universitaria de la UNJBG, fue sometido al proceso de secado en forma similar al rastrojo del alimento vegetal del cuy.

Los substratos fueron expuestos durante dos semanas al sol removiendo y mezclando el material cada dos a tres dias.

Los substratos de la mezcla uno después que fueron acondicionados fueron mezclados con agua y agregados al prefermentador constituido por un depósito cilindrico de polietileno de 230 litros de capacidad. Se agregó un volumen de 30 litros de excremento de cuy soleado, 60 litros de rastrojo del alimento vegetal del cuy también soleado y 30 litros de agua de caño. El agregado de los materiales sólidos se hizo sin someterlos a presion, mezclándolo uno con otro y con el agua poco a poco dentro del prefermentador con ayuda de un palo. Para el agregado de los substratos y el agua se utilizó un balde de 20 litros de capacidad.

Los substratos mezclados con el agua dentro del prefermentador, sin tapa, fueron dejados a la intemperie durante tres días. Luego se agregó dentro del prefermentador, poco a poco y haciendo movimientos de mezcla con ayuda de un palo, 60 litros de agua. Se dejó nuevamente el prefermentador con los substratos a la intemperie hasta que adoptó una apariencia de mermelada, momento en que se consideró como el término de la prefermentación. En este lapso (26 dias después del mezclado de los substratos en el prefermentador) se hizo un mezclado periódico con ayuda del palo de mezcla. El término de la prefermentación se determinó cuando el excremento de cuy prefermentado que al inicio tuvo una consistencia y forma de una habichuela compacta y pequeña se transformó al ser tocado y ligeramente presionado. entre las yemas de los dedos pulgar e indice, en un material de fácil desmoronamiento.

La mezcla dos se prefermentó por separado en forma similar a la mezcla uno con la sola diferencia que el rastrojo de la comida vegetal del cuy soleado y el residuo de grass soleado fueron mezclados previamente en proporciones iguales para constituir un solo substrato antes de ser agregados al prefermentador, de tal modo que este substrato mezcla y el excremento de cuy constituyeron los dos materiales que se trabajó para la 
prefermentación como si hubieran sido los substratos de la mezcla uno.

Se introdujo el prefermentado a los biodigestores (de mezcla de substratos uno para el biodigestor uno y mezcla de substratos dos para el biodigestor dos) por la entrada de carga en su parte superior con ayuda de baldes plásticos y de una especie de embudo obtenida de una pepona hasta que se obtuvo un llenado de un volumen de 177 litros (un poco más de las dos terceras partes de volumen del biodigestor) del total de volumen de 228 litros de capacidad del biodigestor uno; y un llenado de un volumen de 152 litros (dos terceras partes de volumen del biodigestor) del volumen total de 228 litros de capacidad del biodigestor dos. Luego se cerraron herméticamente las tapas de entrada de carga de los biodigestores y se incubaron a un costado del bioterio a temperatura ambiente al aire libre.

Se midió el pH y la temperatura de las mezclas de substratos de los biodigestores uno y dos al inicio y periódicamente del proceso fermentativo. El pH se evaluó con ayuda de una cinta indicadora de $\mathrm{pH}$ que se hizo cubrir con el fluido del substrato que se hacia salir del biodigestor después de abrir la llave de muestreo. La temperatura se determinó introduciendo el termómetro dentro del biodigestor por la abertura de la llave de muestreo luego que ésta fue abierta.

Se consideró hubo producción de biogás cuando se observó externamente que la superficie superior del biodigestor inicialmente plana había cambiado a una forma convexa y cuando al golpear con los nudos de los dedos de la mano en la superficie superior y superior externa lateral del biodigestor el sonido que se producia era un sonido seco, no vibrante, a diferencia del sonido que se producía en el inicio de la fermentación que era un sonido no seco, vibrante. Para comprobar si era biogás lo producido se almacenó el biogás del biodigestor en una cámara de llanta luego se abrió la llave de ésta para que se condujera el biogás hacia un mechero Bunsen en el cual al ponérsele en contacto con la llama de un encendedor originara una llama de fuego como comprobación de que el gas producido era biogás. Este biogás se clasificó por la calidad en buena, regular o mala. Biogás de buena calidad cuando origina una llama azul clara constante; de regular calidad si origina una llama azul naranja; y de mala calidad cuando la llama es de color naranja rojiza.

La primera producción de biogás después del inicio de la fermentación se obtuvo a los 2 meses y 20 dias $(05 / 08 / 2010-25 / 10 / 2010)$ en el biodigestor uno y a $\operatorname{los} 5$ meses y 7 días $(26 / 07 / 2010$ - 02/01/2011) en el biodigestor dos. Las siguientes producciones se obtuvieron cada 15 días cuando se mostraba en el biodigestor las características típicas descritas para la producción de biogás. Se registró ocho producciones de biogás en el biodigestor uno y cinco en el biodigestor dos. El volumen de biogás obtenido para cada producción y biodigestor se determinó midiendo el volumen de biogás que se transfirió desde el biodigestor hacia una cámara de llanta y el volumen total sumando los volúmenes obtenidos para cada producción.
La transferencia del biogás desde el biodigestor a la cámara de llanta se hizo primero conectando la manguera, que estaba fijada a la entrada de aire de la cámara y que a su vez tenía una llave de paso, a la salida de la llave de descarga de biogás del biodigestor; luego abriendo la llave de paso de la manguera de la cámara y la llave de paso de descarga de biogás del biodigestor hasta que la cámara ya no inflaba más o ya no se escuchaba el sonido de transferencia de biogás; finalmente cerrando las dos llaves de paso tanto de la cámara como del biodigestor y desconectando la manguera de la cámara de la llave de paso del biodigestor.

La medición del volumen del biogás contenida en la cámara de llanta se hizo en el laboratorio y aplicando el método por desplazamiento de volumen de agua por el biogás que se hacia salir de la cámara y matemáticamente.

En el método por desplazamiento de volumen de agua el volumen de biogás de la cámara se midió colocando el extremo libre de la manguera de la cámara en el interior de una probeta invertida graduada de 2 litros llena de agua cuya parte inferior estaba ligeramente sumergida en el agua contenido en un balde de 20 litros de capacidad; luego, abriendo la llave de la manguera de la cámara para que el biogás se transfiriera hacia la probeta y desplazara el agua contenida en ella hacia el balde, finalmente la llave de la cámara se cerrara cuando el volumen de agua desplazada alcanzaba los dos litros. Las mediciones se repitieron hasta que no hubo nada de biogás en la cámara de llanta por lo cual en las últimas mediciones se tuvo que presionar manualmente a la cámara de llanta para expulsar todo el biogás contenida en ella.

En el método matemático se aplicó la fórmula:

$$
\mathrm{V}=2 \pi \mathrm{R}^{2}
$$

Donde, $\mathrm{V}=$ volumen de biogás; $\pi=3.1416 ; \mathrm{R}=$ radio externo; $\mathrm{r}=$ radio interno de cámara de llanta inflada. $\mathrm{El}$ radio externo como el interno de la cámara de llanta inflada fue medido con ayuda de una cinta métrica.

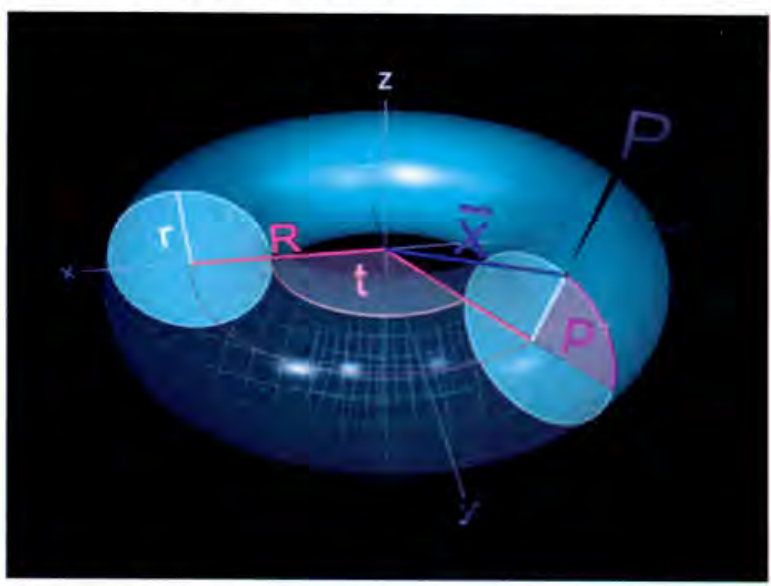

Figura 1: Cámara de llanta con sus variables $\mathrm{R}$ y r para el cálculo del volumen de Biogás que en ella se pudo almacenar 
En cada producción de biogás se midió la presión manométrica con ayuda de un manómetro de columna de agua tanto en los biodigestores como en la cámara de llanta con biogás. La medición se hizo conectando un extremo libre de la manguera del manómetro con el tubo de descarga de biogás del biodigestor o con la manguera de la cámara; para que luego se abriera lentamente la llave de descarga del biodigestor o de la cámara y el biogás se desplazara hacia el manómetro (en forma de u) y entonces el agua de uno de los brazos del manómetro en contacto con el biogás descendiera de nivel y el agua del brazo opuesto ascendiera de tal modo que el incremento o decremento de nivel en uno de los brazos del manómetro se registrara como centímetros de altura de columna de agua de presión de biogás.

\section{RESULTADOS}

Se diseñó y construyó dos biodigestores cilíndricos metálicos ambos con una capacidad de 227 litros, para un proceso de fermentación en batch, anaeróbico, no agitado para la producción de biogás (Figuras 2 y 3 )

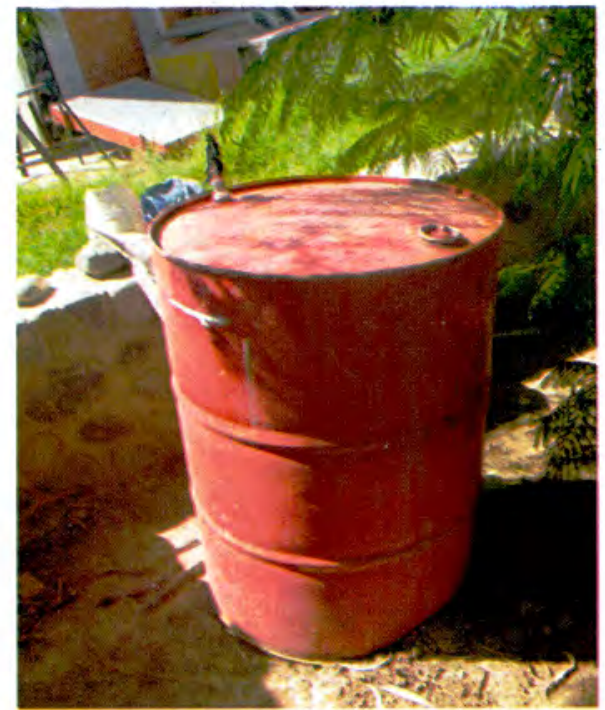

Figura 2: Biodegestor 1

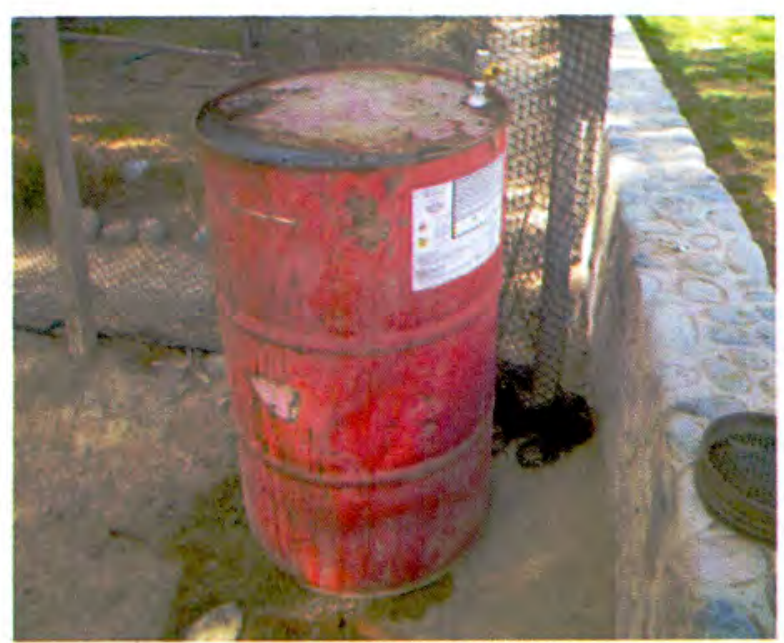

Figura 3: Biodigestor 2

Se obtuvo dos prefermentados con apariencia de sopa o mermelada El primer prefermentado se obtuvo a partir de una mezcla de substratos (mezcla uno) de 30 litros de excremento de cuy, 60 litros de rastrojo del alimento vegetal del cuy y 90 litros de agua, en 30 días (05/07/2010 - 05/08/2010); el segundo prefermentado, a partir de la segunda mezcla de substratos (mezcla dos) de 30 litros de excremento de cuy, 30 litros de rastrojo del alimento vegetal del cuy, 30 litros de residuo de grass y 90 litros de agua, en 26 días (01/07/2010-26/07/2010) (Figura 4)

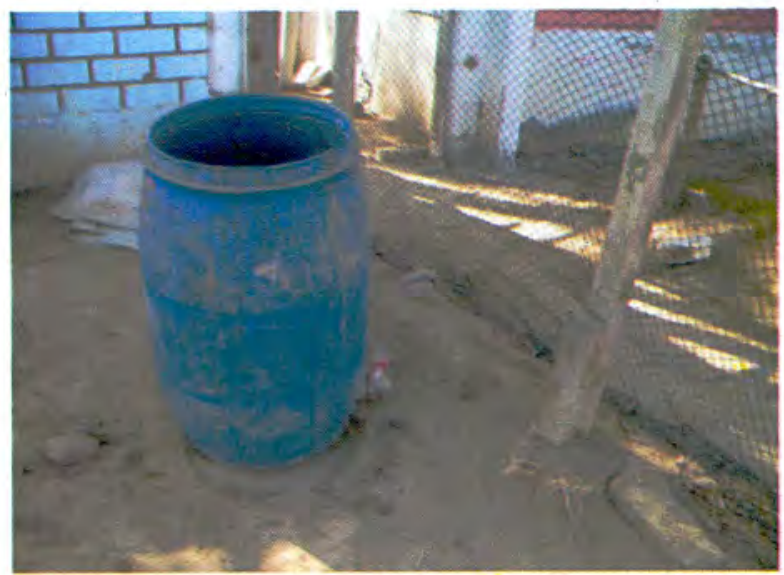

Figura 4: Prefermentado

En los dos biodigestores, en uno con la mezcla de substratos uno y en el otro con la mezcla de substratos dos, se produjo biogás y de buena calidad. Se produjo elevación de la superficie de la tapa de los biodigestores (Figuras 5 y 6 ) y una llama azul clara constante cuando se encendió el biogás en el mechero Bunsen que duró mientras hubo biogás (Figura 7).

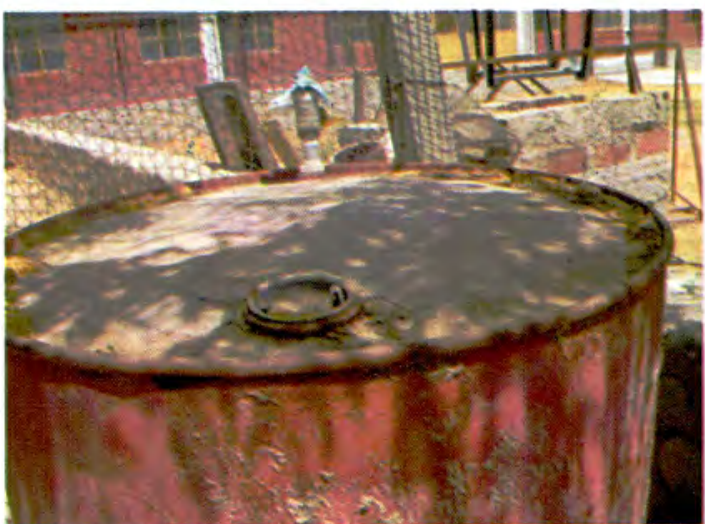

Figura 5: Elevación de Tapa de Biodigestor 1

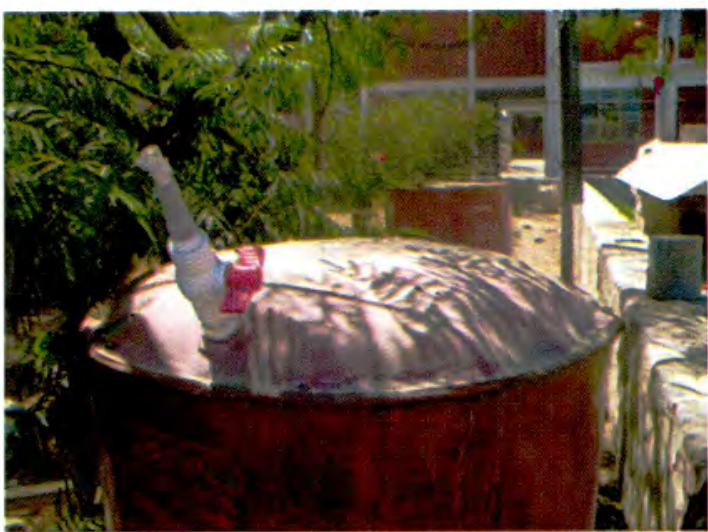

Figura 6: Elevación de Tapa de Biodigestor 2 


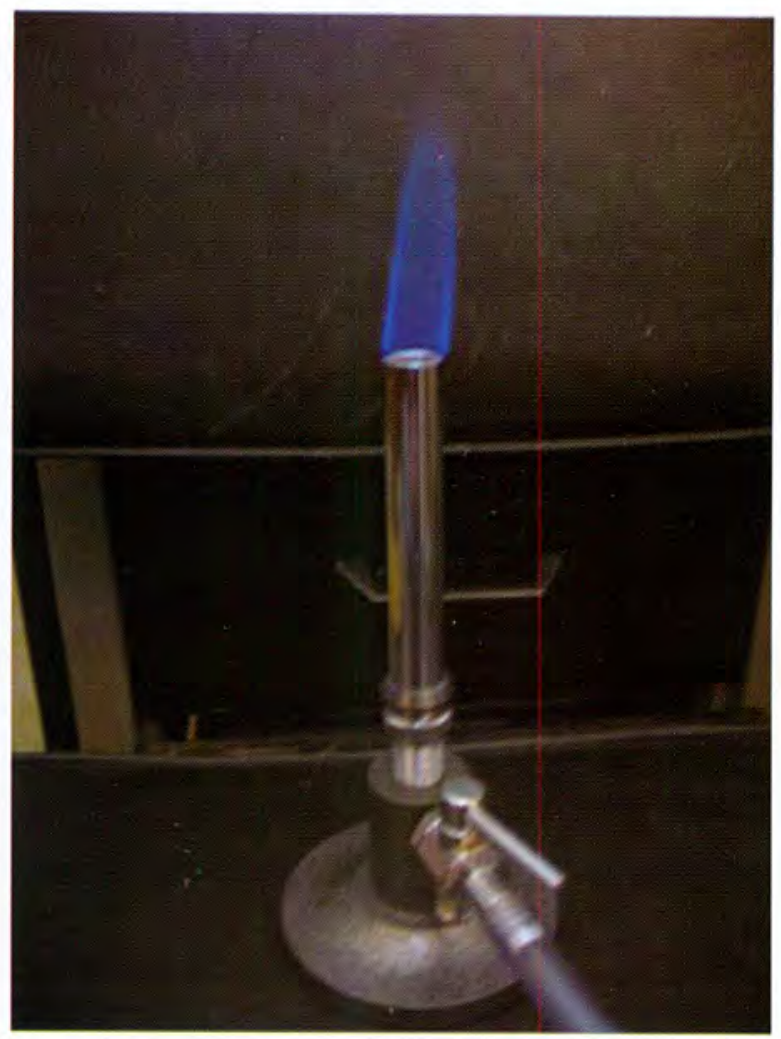

Figura 7: Encendido del Biogás obtenido

Se obtuvo ocho producciones de biogás en el biodigestor uno en un tiempo de fermentación de 7 meses y 6 días (Tabla 1) y cinco en el biodigestor dos en un tiempo de fermentación de 7 meses y. 19 días (Tabla 2). En el biodigestor uno, la primera producción después del inicio de la fermentación se obtuvo a los dos meses y 20 días $(05 / 08 / 2010-25 / 10 / 2010)$ (Tabla 1$)$, en el biodigestor dos a los cinco meses y 7 días $(26 / 7 / 2010-$ 02/01/2011) (Tabla 2).
El lapso entre una y otra producción de biogás tanto en el biodigestor uno como en el dos fue en promedio de 14 días. En el biodigestor uno el volumen de biogás de cada producción osciló entre 6 y 18 litros (Tablas 1 y 2) (Figura 8); en el biodigestor dos, entre 50 y 96 litros (Tablas 4 y 5)(Figura 11); siendo el volumen total de biogás producido en el biodigestor uno de 104 litros con una pendiente de la fase logarítmica de la curva de producción de 19.979 mes $^{-1}$ (Tablas 1 y 3) (Figuras $9 \mathrm{y}$ 10) y en el biodigestor dos de 452 litros con una pendiente de la fase logarítmica de la curva de producción de $158.83 \mathrm{mes}^{-1}$ (Tablas 4 y 6 ) (Figuras $12 \mathrm{y}$ 13).

Tabla 2: Volumen de cada producción de biogás versus lapso de tiempo de fermentación en Batch de la mezcla uno de substratos: excremento de cuy, rastrojo del alimento vegetal del cuy y agua en un biodigestor cilindrico.

\begin{tabular}{ccc}
\hline $\begin{array}{c}N^{\circ} \\
\text { PROD. } \\
\text { BIOGÁS }\end{array}$ & $\begin{array}{c}\text { TIEMPO DE } \\
\text { FERMENTCIÓN } \\
\text { (DIAS) }\end{array}$ & $\begin{array}{c}\text { BIOGÁS DE } \\
\text { CADA } \\
\text { PRODUCCIÓN } \\
\text { (Litros) }\end{array}$ \\
\hline 1 & 81 & 6 \\
2 & 14 & 8 \\
3 & 55 & 12 \\
4 & 15 & 14 \\
5 & 15 & 14 \\
6 & 12 & 16 \\
7 & 15 & 16 \\
8 & 14 & 18 \\
\hline
\end{tabular}

Tabla 1: Volumenes de producciones de biogás obtenidas por fermentación en Batch de la mezcla uno de substratos: excremento de cuy, rastrojo del alimento vegetal del cuy y agua en un biodigestor cilíndrico

\begin{tabular}{cccccc}
\hline $\begin{array}{c}\text { No prod. } \\
\text { de biog. }\end{array}$ & $\begin{array}{c}\text { Fecha prod. } \\
\text { biogás }\end{array}$ & $\begin{array}{c}\text { Tiempo de } \\
\text { ferment. }\end{array}$ & $\begin{array}{c}\text { Lapso entre } \\
\text { prod. }\end{array}$ & $\begin{array}{c}\text { Vol.de biogás } \\
\text { cada produc. }\end{array}$ & $\begin{array}{c}\text { Total } \\
\text { de } \\
\text { biogás }\end{array}$ \\
\hline 0 & $\begin{array}{c}05 / 08 \\
(2010)\end{array}$ & 0 días & 0 días & 0 litros & 0 litros \\
1 & $\begin{array}{c}25 / 10 \\
(2010)\end{array}$ & 2 meses 20 días & 81 días & 6 litros & 6 litros \\
2 & $\begin{array}{c}08 / 11 \\
(2010)\end{array}$ & 3 meses 3 días & 14 días & 8 litros & 14 litros \\
3 & $\begin{array}{c}02 / 01 \\
(2011)\end{array}$ & 4 meses 28 días & 55 días & 12 litros & 26 litros \\
4 & $\begin{array}{c}17 / 01 \\
(2011)\end{array}$ & 5 meses 12 días & 15 días & 14 litros & 40 litros \\
5 & $\begin{array}{c}01 / 02 \\
(2011)\end{array}$ & 5 meses 24 días & 15 días & 14 litros & 54 litros \\
6 & $\begin{array}{c}13 / 02 \\
(2011)\end{array}$ & 6 meses 5 días & 12 días & 16 litros & 70 litros \\
7 & $\begin{array}{c}28 / 02 \\
(2011)\end{array}$ & 6 meses 20 días & 15 días & 16 litros & 86 litros \\
8 & $14 / 03$ & 7 meses 6 días & 14 días & 18 litros & 104 litros \\
\hline
\end{tabular}




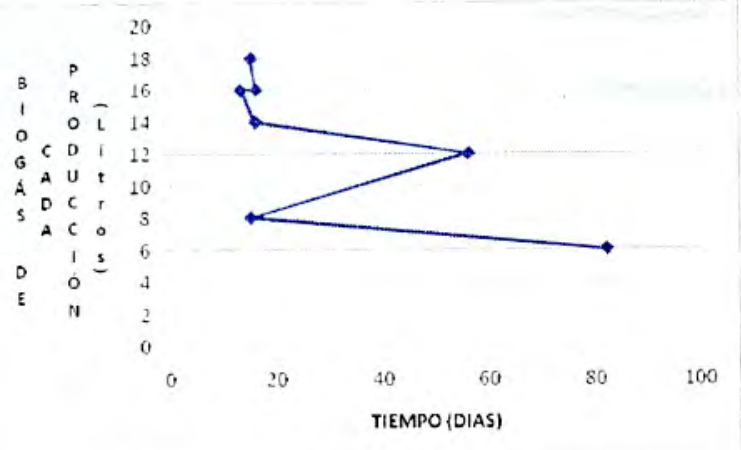

Figura 8: Volumen de cada producción de Biogás versus lapso de tiempo de fermentación en Batch de la mezcla uno de substratos: excremento de cuy, rastrojo del alimento vegetal del cuy y agua en un biodigestor cilindrico

Tabla 3: Volúmenes acumulados de producciones de biogás versus tiempo de fermentación en Batch de la mezcla uno de substratos: excremento de cuy, rastrojo del alimento vegetal del cuy y agua en un biodigestor cilíndrico

\begin{tabular}{ccc}
\hline $\begin{array}{c}N^{\circ} \text { PROD } \\
\text { BIOGÁS }\end{array}$ & $\begin{array}{c}\text { TIEMPO } \\
\text { FERMENT } \\
\text {. (MESES) }\end{array}$ & $\begin{array}{c}\text { BIOGÁS } \\
\text { ACUMULAD } \\
\text { O (LITROS) }\end{array}$ \\
\hline 0 & 0 & 0 \\
1 & 2.6 & 6 \\
2 & 3.1 & 14 \\
3 & 4.9 & 26 \\
4 & 5.4 & 40 \\
5 & 5.9 & 54 \\
6 & 6.2 & 70 \\
7 & 6.7 & 86 \\
8 & 7.2 & 104 \\
\hline
\end{tabular}

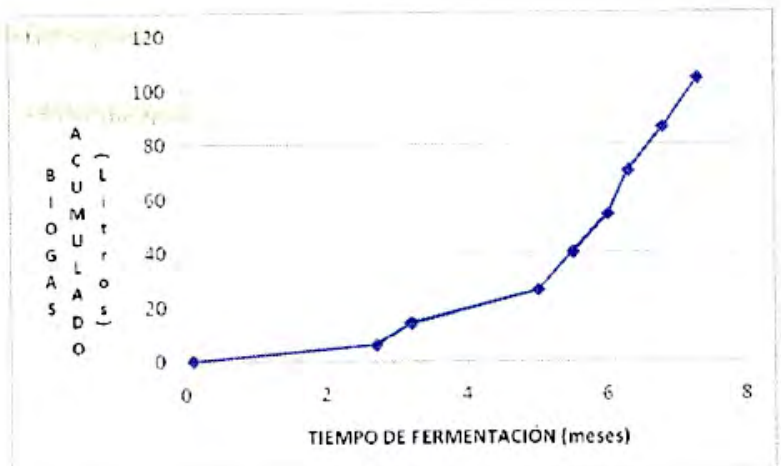

Figura 9: Volúmenes acumulados de producciones de biogás versus tiempo de fermentación en Batch de la mezcla uno de substratos: excremento de cuy, rastrojo del alimento vegetal del cuy y agua en un biodigestor cilíndrico

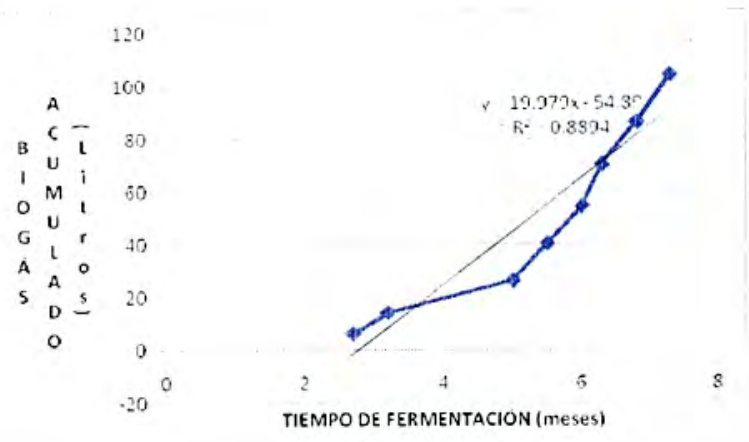

Figura 10: Pendiente de Fase Logaritmica de la curva de producción de biogás relacionando volúmenes acumulados de producciones de biogás versus tiempo de fermentación en Batch de la mezcla uno de substratos: excremento de cuy, rastrojo del alimento vegetal del cuy

Tabla 4: Volumen de cada producción de Biogás versus lapso de tiempo de fermentación en Batch de la mezcla uno de substratos: excremento de cuy. rastrojo del alimento vegetal del cuy y agua en un biodigestor cilindrico

\begin{tabular}{cccccc}
\hline $\begin{array}{c}\mathbf{N}^{\circ} \text { prod } \\
\text { biog }\end{array}$ & $\begin{array}{c}\text { Fecha produc. } \\
\text { Biogás }(\mathbf{2 0 1 1})\end{array}$ & $\begin{array}{c}\text { Tiemp de } \\
\text { fermen. }\end{array}$ & $\begin{array}{c}\text { Lapso de } \\
\text { prod. }\end{array}$ & $\begin{array}{c}\text { Biog de cada } \\
\text { prod. }(\mathbf{L})\end{array}$ & $\begin{array}{c}\text { Vol. total } \\
\text { biog. }\end{array}$ \\
\hline 0 & $\begin{array}{c}26 / 07 \\
(2010)\end{array}$ & $\begin{array}{c}0 \text { días } \\
5 \text { meses }\end{array}$ & $\begin{array}{c}0 \text { dias } \\
5 \text { meses }\end{array}$ & 0 & 0 litros \\
1 & $02 / 01$ & $\begin{array}{c}7 \text { dias } \\
7 \text { dias }\end{array}$ & 80 & 80 litros \\
2 & $17 / 01$ & $\begin{array}{c}5 \text { meses } \\
22 \text { dias }\end{array}$ & 15 dias & 78 & 158 litros \\
3 & $01 / 02$ & $\begin{array}{c}6 \text { meses } \\
6 \text { días }\end{array}$ & 15 dias & 66 & 224 litros \\
4 & $13 / 02$ & $\begin{array}{c}6 \text { meses } \\
18 \text { días }\end{array}$ & 12 dias & 96 & 320 litros \\
5 & $28 / 02$ & $\begin{array}{c}7 \text { meses } \\
5 \text { dias }\end{array}$ & 15 dias & 82 & 402 litros \\
6 & $14 / 03$ & $\begin{array}{c}7 \text { meses } \\
19 \text { días }\end{array}$ & 14 dias & 50 & 452 litros \\
\hline
\end{tabular}


Tabla 5: Volumen de cada producción de Biogás versus lapso de tiempo de fermentación en Batch de la mezcla dos de substratos: excremento de cuy, rastrojo del alimento vegetal del cuy y residuos de grass y agua en un biodigestor cilindrico

\begin{tabular}{ccc}
\hline $\begin{array}{c}\mathbf{N}^{\circ} \\
\text { PROD } \\
\text { BIOG }\end{array}$ & $\begin{array}{c}\text { TIEMPO } \\
\text { DE } \\
\text { FERMENT. } \\
\text { (DIAS) }\end{array}$ & $\begin{array}{c}\text { BIOG. } \\
\text { DE CADA } \\
\text { PRODUC. } \\
\text { (Litros) }\end{array}$ \\
\hline 1 & 160 & 80 \\
2 & 15 & 78 \\
3 & 15 & 66 \\
4 & 12 & 96 \\
5 & 15 & 82 \\
6 & 14 & 50 \\
\hline
\end{tabular}

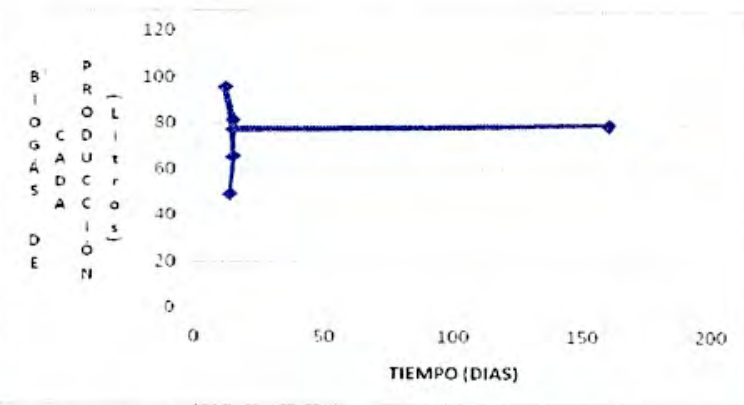

Figura 11: Volumen de cada producción de Biogás versus lapso de tiempo de fermentación en Batch de la mezcla dos de substratos: excremento de cuy, rastrojo del alimento vegetal del cuy y residuos de grass y agua en un biodigestor cilindrico

Tabla 6: Volúmenes acumulados de producciones de biogás versus tiempo de fermentación en Batch de la mezcla dos de substratos: excremento de cuy, rastrojo del alimento vegetal del cuy y resíduos de grass y agua en un biodigestor cilindrico

\begin{tabular}{ccc}
\hline $\begin{array}{c}\mathbf{N}^{\circ} \\
\text { PROD. } \\
\text { BIOG. }\end{array}$ & $\begin{array}{c}\text { TIEMPO } \\
\text { FERMENT } \\
\text { (MESES) }\end{array}$ & $\begin{array}{c}\text { BIOGÁS } \\
\text { ACUMULADO } \\
\text { (LITROS) }\end{array}$ \\
\hline 0 & 0 & 0 \\
1 & 5.2 & 80 \\
2 & 5.7 & 158 \\
3 & 6.2 & 224 \\
4 & 6.6 & 320 \\
5 & 7.2 & 402 \\
6 & 7.6 & 452 \\
\hline
\end{tabular}

\section{DISCUSIÓN}

Un biogás de buena calidad origina una llama de color azul transparente sin emisión de males olores (Borroto. 1997). El biogás obtenido ha presentado estas características.

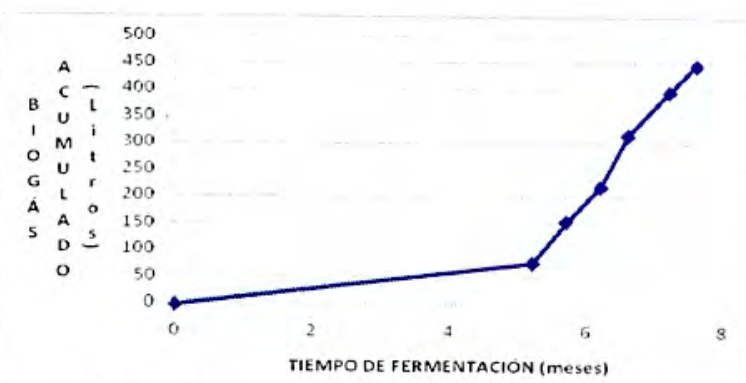

Figura 12: Volúmenes acumulados de producciones de biogás versus tiempo de fermentación en Batch de la mezcla dos de substratos: excremento de cuy, rastrojo del alimento vegetal del cuy y residuos de grass y agua en un biodigestor cilindrico

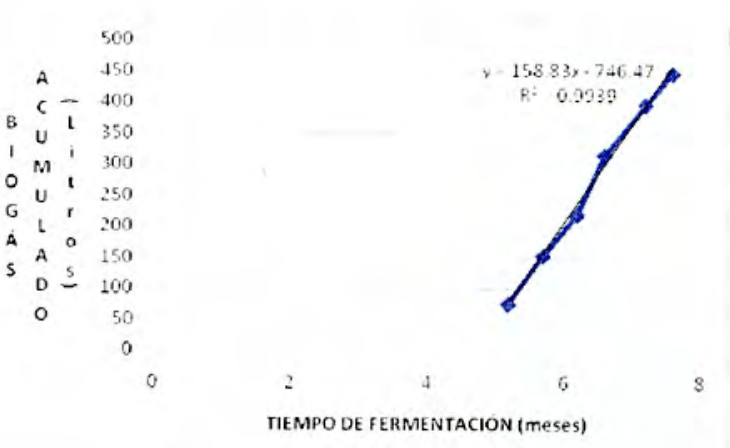

Figura 13: Pendiente de fase logaritmica de la curva de producción de biogás en función de los volumenes acumulados de producciones de biogás versus tiempo de fermentación en Batch de la mezcla dos de substratos: excremento de cuy, rastrojo del alimento vegetal del cuy

El volumen de cada producción de biogás, obtenido cada 14 días en promedio, mayor en el biodigestor dos. se relaciona con una mayor biodigestión. una mejor fermentación que es posible se deba a que fue un mejor medio de fermentación la mezcla de substratos dos. asi mismo, el inóculo microbiano que alli estuvo presente.

El mayor volumen total de biogás producido en el biodigestor dos (452 litros) es un valor muy significativo. Si este valor se divide entre el volumen de medio fermentativo del biodigestor lo que se obtiene es un valor que es cinco veces más a lo que se ha obtenido en investigaciones a nivel de laboratorio trabajando con rúmen bovino (Valencia y col, 2011). Lo obtenido como volumen de biogás total tanto en el biodigestor uno como dos es un resultado satisfactorio que aún podria ser mejorado. En Tacna trabajando con excremento de cuy en anteriores trabajos se ha obtenido muy poco biogás y de mala calidad (Delgado, 2006).

\section{CONCLUSIONES}

En las condiciones trabajadas se concluye en lo siguiente:

1. Se diseñó y construyó dos biodigestores cilindricos metálicos con una capacidad de 227 litros, anaeróbicos, no agitados para una fermentación en batch de producción de biogás. 
2. En base a un proceso aeróbico a partir de la mezcla de substratos uno (excremento de cuy, rastrojo del alimento vegetal del cuy y agua) y de la mezcla de substratos dos (excremento de cuy, rastrojo del alimento vegetal del cuy, residuo de grass y agua) se obtuvo dos prefermentados que constituyeron el material fermentativo para la fermentación de producción de biogás.

3. Se obtuvo producción de biogás de buena calidad.

4. La producción total de biogás obtenida de la mezcla de substratos uno fue de 104 litros, en un tiempo de fermentación de 7 meses y 6 días; y de la mezcla de substratos dos de 452 litros, en un tiempo de fermentación de 7 meses y 19 dias.

\section{REFERENCIAS BIBLIOGRÁFICAS}

Barra, O. A. y Szockolay, S. V. 1988. Basic Course of Renewable Energy Sources, Italian Ministry of Foreign Affairs, Rome, Italy.p.p. 20-31.

Borroto Nordelo, A. 1997. El VerdaderoCosto de la Energía. Taller Caribeño de Energía y Medio Ambiente. Cienfuegos, Cuba. $10 \mathrm{p}$

Campos Avella, J.C. 1999. La Eficiencia Energética en la Gestión Empresarial. Taller Caribeño de Energia y Medio Ambiente. Cienfuegos, Cuba. $10 \mathrm{p}$.

Comisión Nacional de Energía. 1993. Programa de Desarrollo de las Fuentes Nacionales de energía. La Habana. Cuba.

Delgado T., Victorino. 2006. Producción De Biogás De Estiércol De Cuy (Cavia porcelus). ESBI. FACI. UNJBG. Tacna-Perú.

Ferrer Marti, Ivet et al. 2009. Producción de biogás a partir de residuos orgánicos en biodigestores de bajo costo. Universidad Politécnica de Catalunya. España. https://upcommons.upc.edu/handle/123456789/15118 3?locale $=$ es
Hernández Carlos. 1990. Segundo Forum Nacional de Energia: Biogás. La Habana. 132 p.

Johanna S, C. y Col. 2007. Caracterización microbiológica de lodos anaerobios utilizados en el tratamiento de la fracción orgánica de los residuos sólidos urbanos. Scientia et Technica Año XIII, No 35 , Agosto de 2007. Universidad Tecnológica de Pereira.

Macola, B. 1995. Desechos del agro, su aprovechamiento para obtener energía. p.p. 17-41.

Martina P., Corace J., A eberhard A., Aeberhard R. 2009. Construcción de un biodigestor pequeño para su uso en investigación y docencia. Primeros ensayos. Dpto. de Termodinámica - Fac. Ingenieria - Univ. Nacional del Nordeste. Argentina.

Turzo, E., Gutierrez., More, Ana., Ortega, M. y Sanz, A. 1984. Estudio del tiempo de retención (T.R.) y de sinergia de deyecciones de ganado, en el proceso de fermentación anaerobia. Madrid: Instituto Nacional de Investigaciones Agrarias. pp. 6-47.

Valencia y Col. 2011. Digestión anaeróbica de rúmen bovino en laboratorio y determinación química pre y post tratamiento. Livestock Research for Rural Development 23 (2) 2011 .

\section{Correspondencia:}

Daladier Miguel Castillo Cotrina Ciudad Universitaria Fundo "Los Granados" Av. Miraflores s/n. Tacna. Perú daladiercastillo@hotmail.com 